\title{
Developing a tool to measure interest in audiences of a virtual planetarium show
}

\author{
Jesica L. Trucks \\ Abrams Planetarium/Department of Physics and Astronomy, \\ Michigan State University, East Lansing, Michigan, 48824 \\ Gloria I. Lopez \\ Department of Psychology, Michigan State University, East Lansing, Michigan, 48824 \\ Kathleen A. Hinko \\ Department of Physics and Astronomy and Lyman Briggs College, \\ Michigan State University, East Lansing, Michigan, 48824 \\ Shannon Schmoll \\ Abrams Planetarium, Michigan State University, East Lansing, Michigan, 48824
}

\begin{abstract}
Informal learning environments often have a clear ambition to spark interest [1]. People also need multiple exposures to content $[2,3]$ to learn. The Dome+ model, with its principles of interest, identity, and agency, was developed to guide the construction of the Big Astronomy Project consisting of a planetarium show plus additional resources, to support audiences in extending engagement beyond the physical space of the planetarium. A main design principle was sparking interest through the immersive environment of the show. The Big Astronomy Project released a show as a virtual YouTube $360^{\circ}$ stream due to the COVID-19 pandemic. Here we test the utility of the four-phase interest model [4] to characterize interest surrounding the virtual show for use in our larger dataset. The four-phase model suggests people progress from earlier phases of situational interest induced by the environment to later phases of individual interest marked by self-driven engagement. We use this model to characterize the role the show plays in audience interest and look for the role of interest in a virtual environment. We used focus groups with audience members on our premiere day of the planetarium show consisting of eight individuals, and included follow-up interviews with five of those individuals to understand how they continued their engagement with the Big Astronomy Project. Everyone indicated that they chose to watch the show because of an established interest in astronomy. Since self-induced engagement is an aspect of individual interest, we placed all participants in phases 3 to 4 . Our data lacked people who fell into the situational interest phases. We suggest that virtual shows will attract individuals who have an individual interest. We plan to use this research as a tool for the analysis of the larger dataset that includes a more diverse set of individuals.
\end{abstract}

2021 PERC Proceedings edited by Bennett, Frank, and Vieyra; Peer-reviewed, doi.org/10.1119/perc.2021.pr.Trucks

Published by the American Association of Physics Teachers under a Creative Commons Attribution 4.0 license.

Further distribution must maintain the cover page and attribution to the article's authors. 


\section{MOTIVATION}

Informal physics and astronomy education environments often have an explicit goal of sparking and sustaining interest [1]. Interest can be thought of as a psychological state that consists of emotional and intellectual components that can prompt a person to engage in tasks surrounding a topic. It has been shown to connect to students' physics identity [5], their perception of the relevance of the subject matter to their lives [6], and their ability to participate in communities of practice in physics and astronomy [7]. However, one major difference between formal and informal learning is building interest [1]. Building interest is a key in the planetarium is essential to engage people in the short time they are there so they build enough interest to choose to learn more on their own.

The Dome+ model is utilized as set of design principles in the creation of planetarium content and resource. These principles include spark and support interest in astronomy, support identity development by showing real people doing science, and giving the audience the choice to further their engagement by offering multiple avenues of engagement[8]. The Big Astronomy project used this model to create a planetarium show that takes audiences on a tour of three major observatories in Chile and features their diverse staff. This project also includes social media live events, a hands-on activity kit, and a web portal with exclusive content.

The original plan was to premiere the show in May 2020 in planetariums across the world, but COVID-19 shut down a most planetariums[9]. Instead, the project released the planetarium show as a virtual YouTube $360^{\circ}$ stream on September 26, 2020. A YouTube $360^{\circ}$ video allows users to simulate the a planetarium at home by moving their device to "look" around. The user can also click and drag the video to move it around on a computer. Weekly streams on two YouTube channels belonging to the project and a project partner ran through the end of April 2021. Other planetariums also ran the show virtually sporadically during this time.

This paper focuses on characterising audience interest and how this motivated people to engage in the Big Astronomy content. Virtual programming became the norm during the pandemic and is likely to remain a feature of informal learning past the pandemic in some form [9]. It is important to characterize the role of interest in learning in the virtual environment to begin to understand what role the virtual planetarium environment may best play in the future.

The scope of this paper is to test the utility of the fourphase interest model [4] for characterizing interest for use in our larger dataset that includes viewers of the show from all over the world. The four-phase interest model has clear markers of interest and can account for shifts in interest. This work is guided by two questions 1) what interests are people coming to the show with? and 2) how does the Big Astronomy Project affect interest? To determine the utility of the framework for our context, we analyzed data from eight individuals that we spoke to on premiere day. We chose premiere day as a day and date release of a planetarium show was a novel expe- rience for planetariums and this day had the largest audience of any showing. We also include data from five of those individuals who responded for follow-up interviews that focused on how they continued learning about topics they found interesting. The analysis of this subset of individuals will serve as a tool or foundation for further analysis of the larger data set which included regular showings of the virtual planetarium show. We also believe that this work contributes to the broader field of physics and astronomy education by demonstrating how the 4 phase model can be used to understand the fine grained levels of interest in informal education settings.

\section{THEORIES ON INTEREST}

Interest is a psychological state that influences a person to pursue knowledge in a specific content area. This state of interest comprises both an affective and intellectual component. An interest that is based on external cues in a learning environment which could be location or text specific is situational interest [10]. Interest that is self-generated and relates to a person's predisposition to engage in specific content can be classified as individual interest [11]. Schraw \& Lehman (2001) gave an overview, stating situational interest is transitory, activated by the learning environment, and context specific while individual interest is intellectual, affective, self-generated, and enduring [12]. Krapp (2002) speaks about two factors that are connected to an individual interest: 1) intellectual factors that include a person's values and goals; and 2) feelings that an individual associates with a specific topic and postulates that lasting individual interest grows from an interest triggered by a situational interest [11].

Hidi \& Renninger (2006) refined the differences between situational and individual interest with the four-phase model of interest development (see Table I) [4]. This model separates interest into a four-phase progression consisting of Triggered Situational Interest (phase 1), Maintained Situational Interest (phase 2), Emerging Individual Interest (phase 3), and Well-Developed Individual Interest (phase 4). The situational interest in phase 1 is stimulated by environmental or visual cues and typically supports externally gained information. This phase encompasses interest that is generated in the moment by performing a task but not something that a person will generally repeat. This sort of interest may or may not progress to further phases. In phase 2 , situational interest is sustained by personal involvement and/or meaningful engagement with the learning environment. This type of interest is almost exclusively supported externally by the learning environment and conditions. This type of sustained situational interest can sometimes lead to further developed individual interest. Phase 3 and 4 deal with a person's level of individual interest and relate to a person's propensity to engage and re-engage with a specific content area. These phases of interest can be described by a person's knowledge, feelings, and value for a concept. A person's background knowledge of and previous engagement with a content area will lead them 
to choose to engage in future opportunities. Developing phase 3 interest requires some external support, in the form of role models like peers or experts, that contribute to a person's further understanding and an increase in their knowledge, and may not progress to a well-developed individual interest. An individual with a phase 4 well-developed individual interest will generate their own questions from curiosity in a topic and seek out answers, but will also benefit from external support to increase their knowledge base (see Table I).

The four-phase model has been applied in several STEM education contexts. Michaelis \& Nathan (2015) utilized the four-phase model to measure the psychological construct of students in engineering [13]. Rotgans \& Schmidt (2017) tested how situational interest affects the growth of individual interest in primary school students [14]. These examples focus on formal education settings. Within informal education, the focus tends toward how the environment itself helps spark interest in order to support people in learning more. The focus on the environment means the focus is on situational interest and less on those with well developed individual interests. This paper instead focuses on using the four-phase model not only in informal education but also in a virtual environment that is not to the physical environment.

\section{METHODS}

The Big Astronomy Project premiered as a virtual YouTube $360^{\circ}$ planetarium show in September 2020. That day there were three showings in English with a total of 791 general public viewers of all ages. The data analytics of the YouTube channel from premiere day show that audience members tuned in from countries all over the world, and about $55 \%$ identify as men while $45 \%$ identify as women. Of those viewers, eight individuals, 3 female/5 male with ages ranging from about 11 to 64 , agreed to participate in three virtual focus groups immediately after each showing.

We used a semi-structured interview protocol, asking participants what brought them to the show, did the show relate to their interests, did the show spark any new interests, and if they expected to learn more on their own. We then conducted follow-up interviews four months after the initial focus group with five of these individuals. These interviews also used a semi-structured interview protocol, asking each participant if they were inspired to learn more since the show, what they learned about, if they plan to continue to engage in the topic, and how their interests have changed.

The interviews were transcribed and coded initially utilizing a grounded theory approach, wherein the theory is generated from the researcher's observations and interviews [15]. During this analysis interest emerged as a major theme. A second round of emergent coding then focused on how each individual described their interests. Each interview was coded by at least two members of the research team. Codes were compared and discussed between the team members. Codes were in $100 \%$ agreement in terms of both code counts and code labels. Codes describing viewer interests can be found in Table II. There were also secondary codes applied to each interest code to signify if the interest was something the individual had coming into the show, or something that was sparked by the show. We found that each team members codes were in $100 \%$ agreement. Descriptions and examples of our codes are shown in Table II.

We then applied the four-phase interest model to these individuals establishing where they were before engaging in Big Astronomy and determining any movement between the phases. We determined each individual's starting place in the phases by their descriptions of who they were (e.g. student or job description), their previous knowledge surrounding astronomy, and the value they placed on astronomy.

\section{ANALYSIS}

During focus groups we spoke to people with different backgrounds and incoming interests, though all shared an existing interest in astronomy. Each individual was assigned a letter $(A-G)$ in the order they were interviewed them. All the individuals made the choice to engage with the planetarium show because of a previous interest in astronomy. Since characteristics of phase 3 and 4 involve self-induced engagement, meaning people actively seek out content, we placed all of the individuals in either phase 3 to phase 4. (see in Figure 1). We placed each individual in their own location based on who

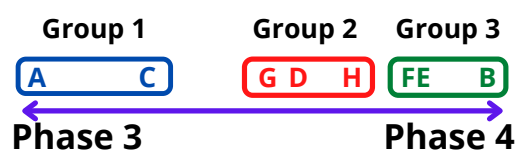

FIG. 1. Individuals initial placement on the Phase 3-4 spectrum

they were, their perceived level of astronomy knowledge, and the value that they placed on astronomy. We determined their perceived knowledge base based on a combination of what they do for a living, and how often and how much they spoke about their interest in astronomy. We found those who are placed higher on the interest phase model had more interest codes related to astronomy. We found differences between some individuals that were placed in phase 4 , and therefore place them into two subgroups within phase 4 .

\section{Phase 3: Emerging Individual Interest}

Group 1 is made up of two individuals who had an interest in general astronomy prior to watching the show, but also gained an interest in something new from watching. These individuals, a 6th grader (Person A) and a university employee (Person $\mathrm{C}$ ), have no ties to the astronomy field besides having an interest in learning more. Person A only had a 5th grade knowledge of astronomy prior to coming to the show, but placed value on astronomy and showed a desire to learn more. They placed low in phase 3. While Person C spoke of going to other astronomy events whenever they can and stated that they process telescope proposals, therefore this placed 
TABLE I. The 4-Phase Interest Development Model

\begin{tabular}{ccc}
\hline \hline Phase & Description [4] & Example Person \\
\hline $\begin{array}{c}\text { Phase 1: } \\
\text { Triggered Situational }\end{array}$ & $\begin{array}{c}\text { stimulated by environment; fleeting no re-engagement; } \\
\text { needs support to engage; positive or negative feelings }\end{array}$ & $\begin{array}{c}\text { watched the show } \\
\text { for a few minutes then leaves }\end{array}$ \\
\hline $\begin{array}{c}\text { Phase 2: } \\
\text { Maintained Situational }\end{array}$ & $\begin{array}{c}\text { stimulated by environment;will re-engage with content; } \\
\text { externally supported to engage with others; positive feelings }\end{array}$ & $\begin{array}{c}\text { watched the show } \\
\text { to the credits then leaves }\end{array}$ \\
\hline $\begin{array}{c}\text { Phase 3: } \\
\text { Emerging Individual }\end{array}$ & $\begin{array}{c}\text { likely self-induced engagement; pose questions to get } \\
\text { answers to support/gain knowledge; positive feelings; } \\
\text { value for topic }\end{array}$ & $\begin{array}{c}\text { previous interest in astronomy; chose } \\
\text { to come to the show; limited } \\
\text { knowledge; wants to learn more }\end{array}$ \\
\hline $\begin{array}{c}\text { Well-Developed } \\
\text { Individual }\end{array}$ & $\begin{array}{c}\text { self-induced engagement; generate and ask } \\
\text { questions to seek out answers; positive } \\
\text { feelings; higher value in topic }\end{array}$ & $\begin{array}{c}\text { previous interest in astronomy; chose } \\
\text { to see to the show; significant knowledge; } \\
\text { wants knowledge growth; high value for topic }\end{array}$ \\
\hline \hline
\end{tabular}

TABLE II. Code Descriptions and Examples

\begin{tabular}{|c|c|c|}
\hline Code & Description & Example Quote \\
\hline Interest:Astronomy & Interest related to astronomy & $\begin{array}{l}\text { "I've learned more about astronomy because I've gone to other opportunities } \\
\text { that came up [...] because I'm just interested" }\end{array}$ \\
\hline Interest:NonAstroSTEM & $\begin{array}{l}\text { Interest related to STEM fields } \\
\text { excluding astronomy }\end{array}$ & "Some of the technical facts were cool and interesting to learn, of course" \\
\hline Interest:Careers & Interest related to Careers & "I'm very much a supporter of STEM careers, always have been." \\
\hline Interest:Misc & $\begin{array}{l}\text { Interests related to } \\
\text { miscellaneous topics }\end{array}$ & $\begin{array}{l}\text { "I've never had a justification to go visit Paranal or CTIO [... [I]t's always } \\
\text { been on my bucket list. And now it's just kind of went a couple notches higher" }\end{array}$ \\
\hline PriorInterest & $\begin{array}{l}\text { Secondary interest code to } \\
\text { indicate prior interest }\end{array}$ & "So I mean, it's just always been an interest to me, astronomy" \\
\hline PostBAInterest & $\begin{array}{l}\text { Secondary interest code to } \\
\text { indicate interest developed by } \\
\text { Big Astronomy content }\end{array}$ & $\begin{array}{l}\text { "I wasn't aware that radio astronomy had that kind of resolution to be picking up } \\
\text { on the development of new solar systems so I'm ready to learn more about that." }\end{array}$ \\
\hline
\end{tabular}

them further along phase 3 as they have a larger knowledge base and still a keen interest in increasing that base. When asked "Why did you come to the show?", Person A stated that "I guess I found like a random love for astronomy." We also asked in a follow up interview "Why were you interested in learning more?", Person C stated "it's always been an interest for me, astronomy." In these responses, we find that the individuals used words such as "love" and"always" to emphasize their strong and prior interest in the topic of the show. These sentiments indicate why they chose to come to the show, indicating their existing interest helped them choose to engage, which further supported their placement in Phase 3.

We asked individuals if there was anything in the planetarium show that sparked some new interest in them. For this group, their new interests involved the telescopes featured in the show. Person A "definitely want[ed] to learn about the giant telescopes", while Person C was more focused on "how radio waves are transformed into visual [images]" and also stated "my fascination with astronomy, which is just growing, even more so after seeing this! The use of the words "definitely" and "growing" and being able to name something new they wanted to go learn about indicates a shift in knowledge and a strong desire to continue to learn more. The Big Astronomy show seems to have supported their interest, and they wish to seek out further engagement with astronomy, indicating some movement towards Phase 4.

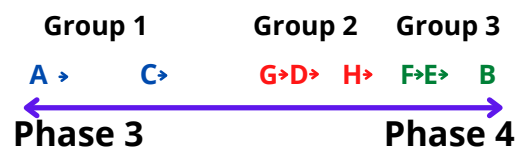

FIG. 2. Individuals movement along the Phase 3-4 spectrum

\section{Phase 4: Well-Developed Individual Interest}

Six individuals are placed in Phase 4 because they are either informal or formal astronomy educators. They all fit the definitions required for Phase 4 due to their extended previous knowledge of astronomy, high value of astronomy, and curiosity to learn more. These six include three individuals who teach astronomy as a part of their career and three individuals who teach astronomy as volunteers in their community. These groups indicated their previous interest in astronomy 
by making similar statements to Person G who stated "I had always thought of astronomy for years and years."

We found that the phase 4 group could be split into two groups: those who gained some new interest during the show, group 2, and those whose existing interests were simply reinforced, group 3. In group 2 Person $\mathrm{G}$ and Person $\mathrm{D}$ have a similar knowledge base, and value for astronomy. Person $\mathrm{G}$ holds a leadership position in their local astronomy club and participates in occasional outreach events for the general public in their community. Person D was placed slightly farther along on the phase 4 interest transition as they regularly perform outreach events for their community at their local library. The last in group 2 is person $\mathrm{H}$ whom we placed further along as they run their own planetarium, and place a very high value on learning new content so they can share with their community. Group 2 discovered some new information during the show which they wanted to learn more about mostly pertaining to the telescopes featured in the show, particularly the radio telescopes. For example, Person D stated "I wasn't aware that radio astronomy had that kind of resolution to be picking up on the development of new solar systems so I'm ready to learn more about that." Another topic that piqued some interest was the careers featured in the show, where Person H stated "I think that really encourages me to tell other young people, okay, you can be astronomers, and here's an example. Look at them.". There were clear gaps in their knowledge, suggesting they were not fully up to date on major discoveries. However, by the nature of their roles in teaching astronomy, they had a fairly well-developed individual interest as well. These individuals seem to be at an earlier or transitional stage between 3 and 4 .

Group 3 consists of those phase 4 individuals whose interests were only reinforced by the show. For this group the show did not spark any new interests and at most helped them gain a few new pieces of information about those existing interests. Two of the individuals already had a deep interest in the astronomy happening in Chile, due to planned trips to visit some of the sites featured in the show. These two are placed at their location in Fig. 1 due to their high knowledge of astronomy in Chile specifically as well as their desire to share that knowledge and their interest with others. Person B is is placed at the highest point because they are a university professor in astronomy, who had a deep understanding of astronomy in Chile, who runs a planetarium and they did not learn anything new from the show. Person E stated that they were "somewhat familiar with a number of those observatories just from being generally interested in astronomy and trying to keep up with things" and that "some of the technical facts were cool and interesting to learn, of course." We can see from the language ("cool", "interesting") that these two individuals used that they valued new knowledge from their experience with the show, but the level of new knowledge gained was more trivial. The third individual, Person B, teaches astronomy at the university level and besides his general interest in astronomy itself this experience reinforced his interest of "going to visit [·] Paranal or CTIO [...], it's al- ways been on my bucket list. And now it's just kind of went a couple of notches higher because yes, I gotta get down there."

\section{DISCUSSION AND FUTURE WORK}

The planetarium show and extended resources of Big Astronomy supported the interests of everyone we interviewed on premiere day. We also discovered that those lower on in the four-phase interest model are being supported to more specific interests related to telescopes or careers, two of the learning goals of this project. While for those in Phase 4, this experience was further support for their existing interests. Those in phase 4 showed two separate groups. One group already had extensive knowledge of astronomy in Chile, while a more transitional group that was still gaining new knowledge and interest in astronomy in Chile specifically but still had established connections to teaching astronomy.

Our data has a lack of people who fall into the situational interest phases. This suggests the very nature of virtual learning tends to attract people who already have individual interest. We postulate that those who fall into the lower phases could have elected not to speak with us or did not watch the entire planetarium show. Unlike a physical planetarium, people can leave a virtual planetarium show at any time indicating their situational interest was not maintained. In future work with a larger data set, that will include interviews with audience members who watched in a physical planetarium, we will be able to test these hypotheses.

Individuals we spoke to already had an existing interest in astronomy. If future analysis of the larger data set determines that most individuals who engage with this virtual content have a previous interest in astronomy, this could imply virtual content could be more supplemental and in depth to target those individuals who have deeper interests in the content.

The data presented in this paper is a subset or our collected data which is ongoing. Our data also includes other interviews taken at regular subsequent showings of the planetarium show. We also recruit interview subjects from surveys disseminated after each planetarium show and live event. Our data collection is ongoing in addition to the eight interviews we discuss in this manuscript we have had 4 subsequent focus groups, 17 individual interviews, as well as over 250 survey responses. We plan to use the research in this manuscript as a tool for the analysis of the larger data set in the future. This will need to be adjusted for the larger data set, because that data set includes a more diverse set of individuals as premiere day was not representative of the entire sample. Finally, this research could also be a useful tool for future informal learning projects that incorporate virtual content.

This project is funded by NSF Advancing Informal STEM Learning program (\#1811436). The team includes Associated Universities, Inc., Assoc. of Universities for Research in Astronomy, Michigan State Univ., California Academy of Sciences, Astronomical Society of the Pacific, Peoria Riverfront Museum, Ward Beecher Planetarium. 
[1] NRC, edited by Learning Science in Informal Environments: People, Places, and PursuitsP. Bell, B. Lewenstein, A. W. Shouse, and M. A. Feder (National Academies Press, 2009).

[2] J. Minstreall, Teaching (Association for Supervision and Curriculum Development, Alexandria, VA, 1989) Chap. Teaching science for undestanding, pp. 129-149.

[3] G. Posner, K. Strike, P. Hewson, and W. Getzog, Accomodation of a scientific conception: toward a theory of conceptual change, Science Education 66 (1982).

[4] S. Hidi and K. A. Renninger, The four-phase model of interest development, Educational Psychologist 41, 111 (2006).

[5] Z. Hazari, G. Sonnert, P. M. Sadler, and M.-C. Shanahan, Connecting high school physics experiences, outcome expectations, physics identity, and physics career choice: A gender study, Journal of Research in Science Teaching 47, 978 (2010), https://onlinelibrary.wiley.com/doi/pdf/10.1002/tea.20363.

[6] A. Nair and V. Sawtelle, Operationalizing relevance in physics education: Using a systems view to expand our conception of making physics relevant, Physical Review Physics Education Research 15, 10.1103/PhysRevPhysEducRes.15.020121 (2019).

[7] C. Fracchiolla, B. Prefontaine, and K. Hinko, Community of practice approach for understanding identity development within informal physics programs, Physical Review Physics Education Research 16, 10.1103/PhysRevPhysEducRes.16.020115 (2020).

[8] J. L. Trucks, K. Hinko, and S. Schmoll, Extending learning beyond the planetarium with the dome+ model, in Physics Ed- ucation Research Conference 2020, PER Conference (Virtual Conference, 2020) pp. 545-550.

[9] S. Schmoll, J. Trucks, and K. Hinko, Research Project Current State of Planetariums during the COVID-19 Pandemic, Tech. Rep. (International Planetarium Society, September 2020).

[10] S. Hidi, Interest and its contribution as a mental resource for learning, Review of Educational Research 60, 549 (1990), https://doi.org/10.3102/00346543060004549.

[11] A. Krapp, Structural and dynamic aspects of interest development: theoretical considerations from an ontogenetic perspective, Learning and Instruction 12, 383 (2002), interest in Learning, Learning to be Interested.

[12] G. Schraw and S. Lehman, Situational interest: A review of the literature and directions for future research, Educational Psychology Review 13, 23 (2001).

[13] J. E. Michaelis and M. Nathan, The four-phase interest development in engineering survey, in American Society of Engineering Education (2015).

[14] J. I. Rotgans and H. G. Schmidt, Interest development: Arousing situational interest affects the growth trajectory of individual interest, Contemporary Educational Psychology 49, 175 (2017).

[15] M. Q. Patton, Qualitative Research and Evaluation Methods, 3rd ed. (Sage, 2002). 